\title{
Multi-Angle Analysis of Technological Innovation
}

\author{
Hui Li, Ruiqi Zhang \\ Faculty of Marxism, Kunming University of Science and Technology, Kunming, China \\ Email: lihui9707@163.com
}

How to cite this paper: $\mathrm{Li}, \mathrm{H}$. and Zhang, R.Q. (2021) Multi-Angle Analysis of Technological Innovation. Open Access Library Journal, 8: e7619.

https://doi.org/10.4236/oalib.1107619

Received: June 7, 2021

Accepted: July 4, 2021

Published: July 7, 2021

Copyright $\odot 2021$ by author(s) and Open Access Library Inc.

This work is licensed under the Creative Commons Attribution International License (CC BY 4.0).

http://creativecommons.org/licenses/by/4.0/

\section{(c) (i) Open Access}

\begin{abstract}
Science and technology is an important result of the progress of human civilization, and technological innovation promotes the development of productivity and has an important impact on the transformation of human thinking. On the one hand, exploring scientific and technological innovation should be based on technology itself, which is already mentioned by most scholars. On the other hand, as the main body of history, human beings are also the main body of scientific and technological innovation. Human beings are the biggest beneficiaries of scientific and technological innovation. Therefore, exploring scientific and technological innovation should not be limited to its intrinsic attribute. It should also clarify the relationship between technology and people, human society, and freedom and necessity, analyze the relationship between technological innovation and human and human society development from multiple angles, and sum up experience and lessons for guidance. Better development of scientific and technological innovation practice activities. Clearly respecting the attitude of science, mastering scientific knowledge, following scientific methods and establishing a scientific spirit better promote scientific and technological innovation and the development of human society.
\end{abstract}

\section{Subject Areas}

Technology and Innovation

\section{Keywords}

Technology, Innovation, Human, Social

\section{Introduction}

Science and technology are an important result of the progress of human civilization and a rational understanding of the laws of the objective world. In mod- 
ern times, the scientific and technological revolution has created a breakthrough and a fundamental approach to the development of productive forces, and has affected the transformation of human thinking. Science and technology have gradually become the focus and core of the struggle between countries for the right to survive, develop and speak. In China's "14th Five-Year Plan" "Recommendations", the first major measure is scientific and technological innovation. $\mathrm{Xi}$ Jinping also pointed out: "Technological innovation is an important engine for the development of human society and a powerful weapon to deal with many global challenges. It is the only way for China to build a new development pattern and achieve high-quality development." This can see the importance of scientific and technological development. The current academic research is mainly focused on exploring the status quo and role of technological innovation and the importance of promoting technological innovation. Since the beginning of the new century, China's scientific and technological strength has increased significantly, and scientific and technological innovation has achieved remarkable results in supporting economic and social development my country has made great strides into the ranks of innovative countries, but there is still a long way to go to build a world of scientific and technological power. Although science and technology are the primary productive forces, we should emphasize that people are both the innovators and beneficiaries of science and technology. In recent years, research results on the relationship between technological innovation and people and human society are lacking. The development of science and technology cannot be driven by innovation, and innovation cannot be separated from the rational development of human beings [1] [2]. This article mainly focuses on analyzing technological innovation from the perspective of people and human society.

\section{The Relationship between Technological Innovation and Mankind}

Humanity is the subject of history and the subject of the historical development of human society, also the subject of material production activities. As the subject, humanity must have subjectivity. Society is inseparable from people. It has always been a system developed around human development. In social history, the occurrence of any event cannot be separated from human activities, and so as the scientific innovation. On the one hand, as far as science is concerned, the birth and development of modern science is the result of the development of human rationality and the embodiment of the active use of human rationality. Based on this inference, science, as an inevitable product of the development of human rationality, is the result of human rationality's correct understanding and grasp of the laws of nature. The innovation of human science is first of all the development of rationality. On the other hand, we look at the concept of innovation from a philosophical point of view. Innovation is a developing concept. Without innovation, there will be no development; without development, inno- 
vation will lose its premise ([3], P. 101). If technology lacks innovation, it will not be able to promote social progress well. At the same time, similar to the concept of science and technology, innovation is also inseparable from people. Innovation is the unity of the practical activities and mental state of people as the subject when transforming the world.

Human beings are not only the main body of technological innovation, but also the biggest beneficiary of technological innovation. Technological innovation is closely related to human beings. Technological innovation is inseparable from the subject of human beings, and human development also depends on technological innovation. Human beings are creatures with the characteristic of rationality, which is an important characteristic that distinguishes it from animals. Technological inventions and scientific discoveries are not social phenomena outside of human beings, but are completely the products of human activities, and are human creations. This can further explain our emphasis on the importance of technological innovation. Without human modernization, there will be no modernization of science and technology, and no technological innovation. Technological innovation and human progress complement each other. Science is the result of human rationality's correct understanding and grasp of the laws of nature, and it is the embodiment of human development. Scientific and technological innovation activities without human participation are unrealistic, and without the help of science and technology, human development will also be limited. Therefore, technological innovation is the development of human beings and the progress of human rationality. To emphasize technological innovation is to emphasize the importance of human development and human rationality.

\section{The Relationship between Technological Innovation and Social Development}

The development of science and the advancement of technology help promote social development. On January 25, 2021, General Secretary Xi Jinping pointed out in a special speech at the World Economic Forum "Davos Agenda" Dialogue: "China will continue to promote scientific and technological innovation. Scientific and technological innovation is an important engine for the development of the world economy and is human society's right response to many global issues' powerful weapon to deal with challenges, and it is also the only way for China to build a new pattern of development and achieve high-quality development." The concept of science and technology as the primary productive force has been deeply rooted in the hearts of the people, and Chinese society has always emphasized respect for technological innovation. The spirit and belief of technological innovation have been established in the whole society.

Technological innovation promotes the transformation and development of human society and contributes to the continuous accumulation of social wealth. Mankind has experienced three revolutions, and advanced productive forces 
continue to replace backward productive forces, all of which can be attributed to the important role of scientific and technological innovation in promoting the leap-forward development of productive forces. Some scientists estimate that, due to technological innovation, the changes in material productivity within 3 years are equivalent to the changes in 30 years in the early 20th century, the changes in 300 years before Newton, and the changes in 3000 years in the Stone Age ([3], P. 105). The important role of scientific and technological innovation in the development of human society is self-evident. Science is the embodiment of knowledge, innovation is the soul of a nation and the inexhaustible driving force for the prosperity of a country. Technological innovation further transforms science and technology into material wealth through the form of knowledge, and plays an important role in promoting and transforming the means, conditions, processes and effects of social material production. Scientific and technological innovation is conducive to the formation of the trend of social science research to further enhance people's ability to create innovation and promote scientific and technological innovation and productivity by leaps and bounds.

From the perspective of social and historical development, although scientific progress and historical progress are not completely synchronized, they are basically parallel. The scientific and technological revolution is not only a breakthrough in the development of productive forces, but also an important driving force in the social development power system. The contribution of science to social development is immeasurable. When inspecting Fujian from March 22 to 25, 2021, General Secretary Xi Jinping pointed out: “China's entry into the first phalanx of scientific and technological development depends on innovation, blindly following the trend will not work, and speeding up technological autonomy. Constantly striving for self-improvement, we must insist on innovation in comprehensive modernization. China's core position is driven by innovation, and innovation is the national policy, actively encouraging and supporting innovation. Innovation has no 'origin', as long as someone can contribute to the country, who will we support." Technological innovation is closely related to social development. In summary, only by correctly grasping the relationship between technological innovation and the development of human society can we not get lost in technological innovation.

\section{Human Beings March from Necessity to Freedom}

Technological innovation is an important condition for human beings to move towards freedom on the basis of knowledge of necessity. Marxist philosophy believes that freedom and necessity are the unity of opposites. Freedom arises from human cognitive and practical activities, just as science arises from the development of human reason and practice. Before knowing and using necessity, human can only be a slave of necessity, man is not free, and this kind of non-freedom not only stays in the bondage of natural forces but also includes the bondage of 
social relations. However, once people have mastered the objective laws, developed in accordance with the objective laws, got rid of blind domination, and entered a conscious and autonomous social state, when a certain goal can be achieved, it means that the necessity gradually transformed into freedom.

Technological innovation can be regarded as people's behavior to benefit mankind on the basis of understanding and grasping objective laws. This behavior includes using the laws to transform the objective world by means of conditions and forms that allow the laws to work, and get rid of the shackles of the inevitable world. Technological innovation is an important condition for human beings to move towards freedom based on the knowledge of necessity. An important condition for freedom on the basis of understanding. Technological innovation promotes human beings from the realms of necessity to freedom. Technological innovation is the activity of human beings to transform the world on the basis of understanding the world. In the process of understanding and transforming the world, the most fundamental thing is to deal with the relationship between freedom and necessity, emphasizing the leap from necessity to freedom. People use technological innovation to make a leap from the inevitable world to the free world. Technological innovation is an important condition for mankind to move from the realm of necessity to the realm of freedom. The development of human society is inseparable from the development of productivity. Technological innovation helps to promote the development of productivity. It allows people to get rid of the two constraints that exist in the inevitable world to a certain extent, that is, the constraints of natural forces and the constraints of social relations. In the past, people could not control the occurrence of earthquakes. Now, with the innovative development of science and technology, with the help of earthquake detection and prediction systems, although people cannot eliminate the disaster of earthquakes, they can minimize the possible damage caused by earthquakes. At the same time, scientific and technological innovation can be further understood as the liberation of mankind, which means that in the process of scientific and technological innovation, people's thoughts and actions are liberated from the forces of nature and social relations to obtain freedom. In summary, technological innovation helps mankind move from necessity to freedom, and from the inevitable world to the free world.

\section{How to Achieve Technological Innovation}

First of all, it is very important to establish an attitude that respects science. The development of science and technology is a two-edged sword. It is going to bring us convenience, but it may also give rise to some problems. We cannot disrespect science because of the existence of problems. The development of history has proved that science can be transformed from the form of knowledge into material wealth, especially natural science is more directly transformed into productive forces, promoting and transforming the means, conditions, processes and effects of social material production. Establishing a correct awareness of respecting science is more conducive to promoting the development of science, 
promoting the development of human thinking and rationality, and thus promoting the better development of society. At the same time, scientific activity is not only a cognitive activity, but also a social activity. People can use science and technology to promote social development, or use it to harm society. We must take a correct view of the relationship between science and technology and social systems, and see that the social functions of science and technology are directly restricted by social relationships and social systems. Under the socialism with Chinese characteristics, the Communist Party of China has always emphasized the importance of science and technology, supplemented by the correct guidance of relevant policies and measures to enable it to develop in a favourable direction. Moreover, social progress should also be aimed at the subject itself, rather than the subject with social progress as the goal. "Progress for the sake of progress" can be regarded as the dissimilation of "progress". During the high epidemic period, there have been negative statements on the Internet, asserting that the past is better than now, the development of science and technology has brought drawbacks, artificial intelligence has continued to develop, and human beings have become "slaves" of mobile phones and are addicted to the online world. To a certain extent, in terms of social reality, people are increasingly dependent on the development of technology, and mechanized production has replaced manual labor. But from a dialectical point of view, technological innovation makes people's lives more convenient, breaks time and space restrictions, and connects all countries in the world. Behind scientific and technological innovation is mankind's unwavering respect and trust in science, and the attitude of respecting science in the heart of a plant.

Secondly, we should master scientific knowledge and follow scientific methods. From the perspective of social and historical development, only by mastering scientific knowledge can we give full play to scientific power. Scientific theories explain the existing and unknown phenomena, which increases the ability of human beings to grasp and predict universal truths. The grasp of scientific knowledge and the innovation of science and technology are innovations obtained from the level of knowledge and understanding of the predecessors, and to achieve development through continuous inheritance and innovation. It is also a kind of respect for the results of falsification. The attitude is not to deny mistake may exist. Xi Jinping emphasized: "Facing the future, we must take meeting domestic demand as the starting point and goal of development, accelerate the construction of a complete domestic demand system, vigorously promote technological innovation and other innovations, and accelerate the advancement of digital economy, intelligent manufacturing, and life and health. Strategic emerging industries such as, new materials, etc., to form more new growth points and growth poles, and strive to open up all links of production, distribution, circulation, and consumption, and gradually form a new development with the domestic cycle as the main body and the domestic and international double cycles mutually promoting under the new situation, we will cultivate our country's new advantages in participating in international cooperation 
and competition." Moreover, the grasp of scientific knowledge cannot be achieved overnight, and scientific methods must be followed. Scientific knowledge appears as a form of knowledge, which requires continuous testing and development. This requires us to go back and examine the premises of scientific theories and explanations, so as to further increase our grasp of knowledge and make scientific theories an important tool for mankind to master the future. Technological innovation is not achieved overnight, but is promoted under continuous experimentation and inspection following the scientific method.

Finally, while using scientific methods to search for scientific knowledge, it is also necessary to establish a scientific spirit. Establishing a scientific spirit requires us to be down-to-earth, seeking truth and being pragmatic, maintaining rational suspicion, not blindly believing in all conclusions, not doubting all conclusions without basis, and forming multiple thinking. The concentrated expression of the spiritual value of science is the scientific spirit. Its primary connotation is seeking truth and pursuing objective truth, which is conducive to people forming a correct world outlook and scientific beliefs. The scientific spirit requires people to combine their personal pursuits with the needs of the country and the hopes of the people in scientific research, to ensure the seriousness and scientific nature of scientific activities, and to coordinate the behavior and social relations of members of the scientific community.

\section{Conclusion}

Technological innovation is closely related to human beings and human society. The continuous advancement of technological innovation promotes the further development of human rationality and promotes the continuous progress of human society. On the contrary, the development of human rationality and the progress of society have also given birth to technological innovation, which further promotes the advancement of mankind from inevitability to freedom. And while advocating scientific and technological innovation, we must also emphasize the importance of respecting science, putting respect for science into reality, and advocating people to further advance scientific and technological innovation on the basis of mastering scientific knowledge, following scientific methods, and carrying forward the spirit of science, so as to promote human society better development.

\section{Conflicts of Interest}

The authors declare no conflicts of interest.

\section{References}

[1] Jiang, C.Y. (2021) Science and Technology Innovation Leading and Supporting the Focus of High Quality Development. Open Herald, 3.

[2] Jiang J. (2021) Prospects and Suggestions for Medium and Long Term Scientific and Technological Innovation Development. Open Herald, 48-55.

[3] Wang, G.Q. and Xu, H.F. (2019) The Methodologies of Marxist Philosophy. Liaoning University Press, Shenyang. 